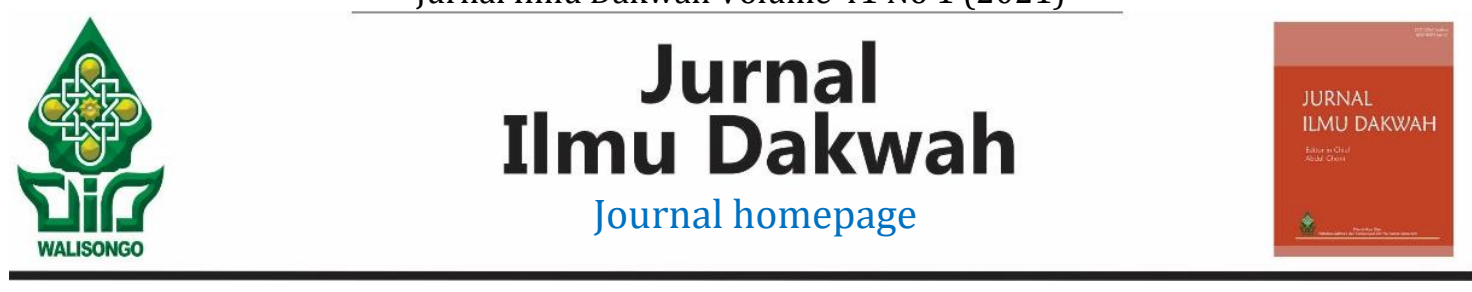

\title{
Perkembangan dakwah Muhammadiyah di Tombolo Pao Kabupaten Gowa
}

\author{
Imran Rifai \\ Universitas Islam Negeri (UIN) Alauddin Makassar \\ Email: rifaiimran224@gmail.com
}

\begin{abstract}
Muhammadiyah as one of the religious community organizations has a mission to make changes in the lives of Muslims to a better condition. Through the strategy of amar ma'ruf nahi munkar as the basis of the movement, Muhammadiyah aims to purify the teachings of Islam which are heavily influenced by mystical things. Including what happened in Tombolo Pao District, the condition of the community is still influenced by animistic beliefs and dynamism with worship practices that are full of heresy, superstition and shirk. Along with the establishment of Muhammadiyah, slowly but surely always provide guidance and enlightenment with da'wah methods based on the Qur'an and Hadith. This type of research uses qualitative methods, data analysis techniques, namely data collection, data reduction, data presentation and drawing conclusions. This paper focuses on the history of the founding of Muhammadiyah and the influence of Muhammadiyah's da'wah thought in Tombolo Pao District, Gowa Regency. The implication is that the da'wah carried out by Muhammadiyah through various sectors and targets of da'wah can be embraced by other religious community organizations, so that it is accepted by the wider community as happened in Tombolo Pao.
\end{abstract}

Keywords: Development, da'wah, Muhammadiyah.

\begin{abstract}
Abstrak
Muhammadiyah sebagai salah satu organisasi masyarakat keagamaan memiliki misi melakukan perubahan dalam kehidupan umat Islam kepada kondisi yang lebih baik. Melalui strategi amar ma'ruf nahi munkar sebagai dasar gerakan, Muhammadiyah bertujuan untuk memurnikan kembali ajaran Islam yang banyak dipengaruhi oleh hal-hal mistis. Termasuk yang terjadi di Kecamatan Tombolo Pao, keadaan masyarakat masih dipengaruhi oleh kepercayaan animisme dan dinamisme dengan praktik-praktik ibadah yang penuh dengan bid'ah, khurafat, takhyul dan syirik. Seiring dengan berdirinya Muhammadiyah, perlahan tapi pasti selalu memberikan bimbingan dan pencerahan dengan metode dakwah berdasarkan Al quran dan Hadis. Jenis penelitian ini menggunakan metode kualitatif, teknik analisis data yakni pengumpulan data, reduksi data, penyajian data dan penarikan kesimpulan. Tulisan ini fokus pada sejarah berdirinya Muhammadiyah serta pengaruh pemikiran dakwah Muhammadiyah di Kecamatan Tombolo Pao Kabupaten Gowa. Implikasinya, dakwah yang dilakukan Muhammadiyah melalui berbagai sektor dan sasaran
\end{abstract}


dakwah bisa dianut oleh organisasi masyarakat keagamaan lainnya, supaya diterima kalangan masyarakat luas seperti halnya yang terjadi di Tombolo Pao.

Kata Kunci: Perkembanngan, dakwah, Muhammadiyah.

\section{PENDAHULUAN}

Manusia merupakan makhluk ciptaan Allah swt, yang kompleks dan unik serta diciptakan dalam integrasi dua subtansi yang tidak dapat berdiri sendiri. Subtansi pertama disebut tubuh (fisik/jasmani) sebagai unsur materi, sedangkan subtansi kedua disebut jiwa (rohani/psikis) yang bersifat sebagai unsur non materi. Dalam keterpaduan kedua subtansi tersebut manusia menjalani hidup dan kehidupan yang kompleks dan unik. Salah satu keunikannya yang mendasar adalah kehidupannya yang dibekali dengan hakikat kemanusiaan (manusiawi) yang terdiri dari (1) hakikat individualitas, bahwa setiap manusia menyadari identitasnya yang tidak sama dengan individu yang lain. Setiap individu menyadari identitasnya yang berbeda secara fisik dan psikis dari individu yang lain. Dalam ketidaksamaan itu, setiap manusia tampil sebagai individualitas dan memerlukan perlakuan sesuai individualitasnya masing-masing. Kemudian (2) hakikat sosialitas berarti bahwa setiap manusia sebagai individu memerlukan individu yang lain; (3) masyarakat harus mampu membatasi diri masing-masing, agar tidak melanggar norma-norma yang berlaku di dalam suatu masyarakat.

Berdasarkan uraian di atas, telah jelas bahwa terbentuknya organisasi dalam tatanan kehidupan masyarakat didasari oleh hakikat kemanusiaan yang pada gilirannya tertuju pada usaha pemenuhan kebutuhan. Kemampuan memenuhi kebutuhannya itu yang merupakan prasyarat penting dalam menempatkannya pada kedudukan sesuai manusia. Melihat kenyataan manajemen sumber daya manusia, bahwa dalam berorganisasi adalah untuk bekerja dalam rangka memenuhi kebutuhannya, sedang sebaliknya kebutuhan itu pula yang menjadi obyek manusia berorganisasi. Apabila organisasi untuk pemenuhan kebutuhan, maka sangat tepat apabila dikatakan bahwa ketaatan kepada Allah SWT juga merupakan kebutuhan beragama manusia, bahkan diakui atau pun tidak merupakan kebutuhan yang paling mendasar secara psikologis.

Salah satu agama yang mengatur hubungan manusia dengan Tuhannya yakni Islam. Bukan hanya itu, namun hubungan diri sendiri dengan orang lain, yang mencakup semua aspek mulai dari urusan dunia sampai akhirat, baik yang menyangkut dosa, pahala, surga dan neraka. Islam pada hakekatnya berfungsi sebagai penghapus terhadap berbagai keterbelakangan, baik yang berkaitan dengan kepercayaan, sistem feodal, penjajahan dan sebagainya. Seperti halnya di Yogyakarta, perilaku penjajah tampaknya semakin tidak bisa dikendalikan. Hal tersebut dikarenakan tekanan Belanda telah merusak jiwa dan moral bangsa. Pada saat itu Islam bercampur baur dengan tradisi berbagai agama dan kepercayaan. Sehingga muncul beberapa kelompok yang mengaku Muslim dipengaruhi oleh pengaruh dan taktik serta strategi Belanda. Selain itu ada juga yang terpengaruh ke dalam paham kuno yang menyesatkan seperti bid'ah, takhayul dan syirik di kalangan masyarakat Islam di Indonesia. Akibat penjajahan Belanda yang berkepanjangan, mengakibatkan kebodohan dan keterbelakangan yang telah melanda Indonesia. Pendidikan hanya dinikmati oleh kalangan bangsawan dan itupun harus mengikuti sistem dan tradisi Belanda. Mulai dari Kota hingga desa terpencil, Belanda berhasil mengobrak-abrik bangsa 
Indonesia. Hal tersebut membangkitkan semangat rakyat Indonesia pada saat itu untuk bersatu dan sekaligus melawan penjajah (Radjab, 1999).

Salah satu organisasi yang eksis dan bertujuan mengajak umat manusia khususnya umat Islam itu sendiri diantaranya untuk taat kepada Allah SWT yakni Muhammadiyah yang didirikan pada tanggal 18 November 1912 oleh KH. Ahmad Dahlan di Yogyakarta. Misi dakwah dari organisasi ini terinspirasi oleh pesan Allah SWT yang memerintahkan umat manusia untuk membentuk suatu kelompok yang senantiasa mengajak kepada kebaikan (amar ma'ruf) dan mencegah sesama manusia dari perbuatan yang mungkar (nahi munkar), sebagaimana yang termaktub dalam QS. Ali Imran/3: 104.

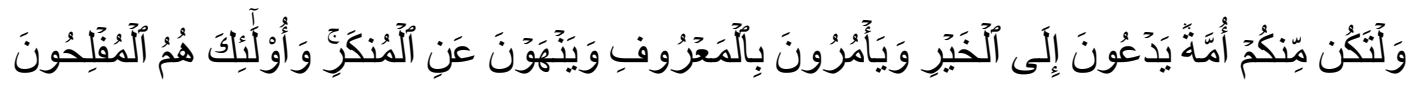

Artinya: "Dan hendaklah ada di antara kamu segolongan umat yang menyeru kepada kebajikan, menyuruh kepada yang ma'ruf dan mencegah dari yang munkar; merekalah orang-orang yang beruntung." (Q.S. Ali Imran/3: 104) (RI, 2010).

Berdasarkan ayat di atas, dapat dipahami bahwa perintah dakwah adalah tanggung jawab umat manusia khususnya umat Islam, hal tersebut dapat lebih efektif bila dilakukan dengan bersama-sama dan hal ini juga mengindikasikan bahwa hakikat sosialitas pada diri manusia merupakan hal yang cukup urgen dalam misi dakwah. Muhammadiyah berdiri atas dasar gagasan pemikiran dari K.H Ahmad Dahlan pada tahun 1912 di Yogyakarta. Muhammadiyah merupakan organisasi Islam dengan berdasarkan pemurniaan atau purifikasi dan langsung merujuk Al Quran dan As Sunnah serta merefleksikan dakwah Amal Ma'ruf Nahi Munkar (Shobron and Azmi, 2011). Muhammadiyah didirikan di Yogyakarta pada tanggal 8 Zulhijjah $1330 \mathrm{H}$. bertepatan 18 November 1912 oleh KH. Ahmad Dahlan. Dia adalah putra ketiga KH. Abu Bakar, seorang khatib di masjid Kesultanan Yogyakarta. KH. Ahmad Dahlan lahir pada tahun 1258 H/1868 M di daerah Kauman. Kegiatan organisasi dimulai sebelum ia mendirikan organisasi Muhammadiyah. Pengalaman hebat diperoleh dalam organisasi tampaknya telah membawanya untuk berhasil memimpin dan mengembangkan organisasi Muhammadiyah di luar Yogyakarta (Lubis, 1993).

Selama berkiprah, Muhammadiyah telah melakukan kegiatan dakwah amar ma'ruf nahi munkar dengan tujuan untuk memurnikan kembali ajaran Islam yang banyak dipengaruhi oleh hal-hal mistik yang merupakan warisan peradaban Hindu-Buddha keseluruh pelosok negeri dan telah memasuki hampir setiap sektor kehidupan masyarakat, seperti sektor ibadah, pendidikan, kesehatan, dan sosial (Al-Qaradhawi et al., 2005). Din Syamsuddin mengungkapkan bahwa Muhammadiyah telah memberikan sumbangsih yang besar kepada bangsa Indonesia melalui gerakan pencerdasan, peningkatan kualitas kesehatan dan kehidupan sosial, pemberdayaan taraf kehidupan ekonomi masyarakat, tentunya sebagai pencerahan kehidupan keberagamaan umat Islam (Karim dkk, 2019). Muhammadiyah sebagai organisasi tentunya memiliki sebuah strategi maupun cara dalam mewujudkan tujuannya. Menurut Kamal, organisasi pada umumnya diartikan sebagai suatu bentuk usaha kerjasama dari kelompok manusia untuk mencapai tujuan (Pasha \& Darban, 2000).

Muhammadiyah dilahirkan sebagai bentuk upaya perubahan dalam kehidupan umat Islam yang lebih baik, misi dan strategi dakwah amar ma'ruf nahi munkar merupakan dasar 
gerakan sosial keagamaan organisasi tersebut. Menurut Syaifullah, Muhammadiyah dituntut untuk menciptakan sebuah dinamisme dan progresifitas dalam menjawab persoalan-persoalan yang terjadi pada umat Islam (Suyuthie, 2010). Persolan yang semakin kompleks dalam kehidupan sosial menjadi cara tersendiri bagi Muhammadiyah untuk memberikan solusi. Langkah kongkrit menurut Kamal di antaranya mampu merefleksikan pendalaman terhadap Al Quran dan As-Sunnah terutama pada surat Ali Imran ayat 104 yang mempunyai makna bahwa umat muslim menyerukan dan melaksanakan kebajikan dan mencegah sebuah kemungkaran. Usaha pemurnian dan pengembalian ajaran Rasulallah SAW kepada umat muslim yang masih berpegang teguh pada nilai-nilai ajaran tradisional yang bersifat tahayul, bid'ah, dan khurafat mempertahankan Islam dari pengaruh luar; menyempurnakan lembaga-lembaga pendidikan yang mampu mencetak pelajar dengan tujuan yang hendak dicapai, serta pengaruh dan dorongan gerakan pembaharuan dalam Islam.

Eksistensi Muhammadiyah di masyarakat Tombolo Pao sangat diakui lebih unggul dibandingkan organisasi Islam lain. Hal tersebut dapat dilihat pada setiap kegiatan keagamaan yang di laksanakan oleh masyarakat, seperti pengajian majelis ta'lim, ceramah hari raya Idul Fitri dan Idul Adha, pengajian, pelatihan da'I dan pelatihan pemulasaran jenazah. Sebagian besar ustadz-ustadz yang mengisi kegiatan-kegiatan tersebut berasal dari Pimpinan Cabang Muhammadiyah (PCM) Pao Tombolo. Adapun tradisi di dalam masyarakat yang mencampuradukkan antara tradisi dan hukum agama, banyak masyarakat yang percaya Takhayul, Khurafat, dan Bid'ah. Serta masih dipengaruhi oleh ajaran animisme dan dinamisme (Mulkhan, 1994). Melihat sebagian besar masyarakat di kecamatan Tombolo Pao yang masih kental dengan pengamalan-pengamalan yang jauh dari AlQur'an dan Al-Sunnah maka perlu adanya pembinaan kepada masyarakat Tombolo Pao agar meninggalkan ajaran-ajaran yang tidak sesuai dengan Al Qur'an dan As Sunnah, dan kembali kepada ajaran yang sesuai dengan ajaran Allah SWT dan Rasullullah SAW dan salah satu penggiat mengembalikan masyarakat kepada jalan Islam yang lurus adalah Muhammadiyah Cabang Pao Tombolo.

Pimpinan Cabang Muhamadiyah Cabang (PCM) Pao Tombolo memiliki peran penting di masyarakat sebagai salah satu lembaga dakwah dan organisasi masyarakat Islam yang eksis. Pimpinan Cabang Muhammadiyah (PCM) Pao Tombolo juga berhasil mengubah pola fikir sebagian masyarakat mengenai perilaku Tahayyul, Bid'ah, dan Khurafat yang masih dilakukan oleh sebagian besar masyarakat yang ada di Kecamatan Tombolo Pao. Berdasarkan penjelasan diatas, Organisasi Muhammadiyah memiliki peran yang sangat besar terhadap perubahan kehidupan beragama masyarakat di Kecamatan Tombolo Pao, Oleh karena itu, tulisan ini ingin mengetahui perkembangan organisasi Muhammadiyah di Kecamatan Tombolo Pao serta mengetahui usaha yang dilakukan Muhammadiyah dalam mencapai tujuan organisasinya di kecamatan Tombolo Pao. 


\section{METODE PENELITIAN}

Penelitian ini menggunakan metode penelitian kualitatif, yaitu kegiatan penelitian untuk memperoleh data lapangan dengan memfokuskan pada masa lalu dan upaya untuk membangun fakta tentang masa lalu. Penelitian ini dilakukan secara sistematis dan objektif dalam mencari, mengevaluasi, dan menafsirkan bukti sehingga sampai pada kesimpulan yang akurat. Penelitian ini bermaksud untuk memahami fenomena atau peristiwa tentang organisasi sehingga menghasilkan data keterangan berupa keterangan lisan dari beberapa orang yang dianggap berpengalaman tentang objek yang diamati serta mengkaji dari beberapa sumber tertulis. Oleh karena itu, teknik pengumpulan data berupa observasi, wawancara dengan tokoh terkait serta melalui salinan tertulis yang berkaitan dengan keberadaan Muhammadiyah di Kecamatan Tombolo Pao.

\section{HASIL DAN PEMBAHASAN}

\section{Sejarah Muhammadiyah di Tombolo Pao}

Tombolo Pao merupakan sebuah kecamatan hasil dari pemekaran dari Kecamatan Tinggimoncong pada tahun 1998. Tombolo Pao merupakan daerah dataran tinggi yang terletak di bagian timur Kabupaten Gowa. Meskipun masyarakat Tombolo Pao telah sejak lama memeluk agama Islam, namun dalam praktiknya masih banyak masyarakat yang menjalankan tradisi dan ajaran nenek moyangnya. Tombolo Pao berada pada bagian timur Kabupaten Gowa, Tombolo Pao merupakan dataran tinggi yang masyarakatnya umumnya hidup dari hasil pertanian. Hal tersebut menjadikan masyarakat Tombolo Pao tidak lepas dari pengaruh-pengaruh kebudayaan lama dari ajaran leluhur terdahulu mereka.

Jauh sebelum Islam masuk ke Tombolo Pao, masyarakat sudah mulai mengenal kepercayaan dan animism dinamisme. Selanjutnya setelah Islam datang, terdapat beberapa ajaran dalam masyarakat yang mencampuradukkan tradisi dan hukum agama, banyak orang percaya pada takhayul dan bid'ah serta masih dipengaruhi oleh ajaran animisme dan dinamisme (Musriadi, 2016). Diantara tokoh perintis Berdirinya Muhammadiyah di Tombolo Pao yakni Samiun. Dia merupakan seorang guru yang berasal dari Bonthain (Bantaeng) yang ditugaskan oleh pemerintah Belanda di Distrik Pao untuk mengajar di sekolah rakyat bersama dua rekannya yang bernama Mangngamporang dan Ba'do pada tahun 1935.

Samiun merupakan tokoh asal Bantaeng yang diutus oleh Pemerintah Belanda ke Tombolo untuk mengajar. Dalam menjalankan tugasnya sebagai seorang guru di Distrik Pao, Samiun senantiasa senang dan aktif untuk berdiskusi dengan tokoh-tokoh masyarakat terutama yang berkaitan dengan pemahaman agama yang berkembang pada saat itu. Guru beliau sekaligus inspirator Samiun dalam mengembangkan paham Muhammadiyah adalah Haji Malawi dari Maros. Haji Malawi (Haji Ba Alwi) yang dimaksud dari uraian diatas adalah

Ayah dari Fathul Muin Daeng Magading, tokoh Muhammadiyah Sulawesi Selatan. Munculnya tokoh-tokoh tersebut, maka dapat diinterpretasikan bahwa awal kedatangan Samiun dari Bantaeng ke Tombolo bukanlah untuk membawa dan mendirikan Muhammadiyah. Tetapi munculnya ide mendirikan Muhammadiyah di Tombolo yaitu setelah aktif mengikuti pengajian pada Haji Malawi di Maros. Mengingat Haji Malawi atau menurut versi Wahab Radjab adalah Haji Ba Alwi merupakan tokoh Muhammadiyah Maros 
yang aktif mengikuti pengajian di Makassar, bahkan dia adalah salah satu pengurus group Muhammadiyah Maros tahun 1929 (Radjab, 1999). Sehingga sangat memungkinkan bahwa dari interaksi Samiun dan tokoh Muhammadiyah tersebut memunculkan ide bagi Samiun untuk mendirikan grup Muhammadiyah di Tombolo Pao. Apalagi sudah menjadi hal yang lazim di Muhammadiyah ketika itu, setiap peserta pengajian diberikan tugas guna membawa dan menyebarkan Muhammadiyah di daerah masing-masing.

Pada sekitar awal tahun 1940-an, melalui Samiun didirikanlah sebuah organisasi Islam, yaitu Muhammadiyah. Organisasi tersebut sebagai wadah atau media dalam mengembangkan paham dan ajaran muhammadiyah yang disebut dengan pimpinan cabang muhammadiyah Tombolo Pao yang masih terkenal hingga sekarang. Pada bulan Januari 1962, group Muhammadiyah Pao Tombolo diresmikan menjadi ranting Muhammadiyah dan berada dalam binaan pengurus Cabang Muhammadiyah Sungguminasa, Pengurus ranting ketika itu sebagai berikut: Ketua; Thalib, Sekretaris; Barang Kasim, Bendahara; Hasan, adapun anggotanya diantaranya; Genda, Lelo, Ruppa, Paru, Kasim, Mamung dan Kadir (Zainuddin, 2021). Sebuah gerakan atau organisasi yang ingin mencapai tujuannya akan selalu menghadapi berbagai macam kesulitan dan rintangan. Kesulitan dan hambatan dalam ditentukan oleh besarnya cita-cita yang ingin dicapai. Sebagai gerakan Islam, Persyarikatan Muhammadiyah tentunya memiliki cita-cita yang cukup tinggi, yaitu: "Menjunjung tinggi dan menegakkan agama Islam agar terwujud masyarakat" Islam yang benar." Oleh karena itu, tidak heran jika tantangannya dan kesulitan yang mereka hadapi cukup berat. Adapun masalah yang dihadapi Muhammadiyah pada awal berdiri di Kecamatan Tombolo Pao antara lain:

a. Tantangan dari kaum adat; Rintangan ini di hadapi Muhammadiyah pada saat kaum adat atau dari golongan bangsawan yang masih kuat berpegang pada tradisi yang telah berabad-abad mereka kerjakan secara turun temurun seperti tradisi nenek moyangnya. Kaum adat ini membenci dan menghalangi Muhammadiyah karena beranggapan apa yang di bawah Muhammadiyah bertentangan dengan tradisi yang mempertahankan apa yang mereka miliki.

b. Tantangan Keluarga; Keluarga atau kerabat warga Muhammadiyah sendiri bahkan yang telah masuk Muhmmadiyah yang masih bersikap konservatif. Mereka beranggapan bahwa Muhammadiyah adalah ajaran baru yang tidak patut di ikuti karena menyesatkan.

c. Tidak adanya dukungan dari pemerintah setempat. Pemerintah sering mengancam ingin membubarkan Muhammadiyah di Tombolo Pao dan mengancam masyarakat yang ikut dengan Muhammadiyah, ini di sebabkan karna pemerintah pada saat itu kurang memahami apa itu Muhammadiyah.

d. Terdapat banyak organisasi Islam baru yang berkembang, seperti Wahdah Islamiyah, As Sunnah (Salafi), Nahdatul Ulama, dan Jamaah Tablig. Organisasi yang tergolong baru tersebut rutin melakukan kegiatan-kegiatan besar.

Itulah beberapa kendala yang dihadapi Muhammadiyah masa awal masuk dan berdirinya di kecamatan Tombolo Pao. Namun berkat usaha dan kerja keras para Pengurus dan Pejuang Muhammadiyah yang tak kenal lelah dan hati teguh, sehingga organisasi Muhammadiyah di kecamatan Tombolo Pao Kabupaten Gowa, kini telah berkembang dan eksis di wilayah tersebut. Meskipun Muhammadiyah sudah ada dan sudah eksis di daerah ini, bukan berarti tidak ada lagimenghadapi hambatan dan tantangan. Karena selama usaha 
belum juga mencapai tujuan, artinya perjuangan dan usaha akan terus dilakukan. Walaupun seriring dengan perjalanan mencapai tujuan tentu terdapat berbagai macam rintangan baru. Karena Muhammadiyah menyadari bahwa setiap langkah pasti selalu menghadapi rintangan, karena apa yang dilakukan adalah usaha untuk impian yang luhur.

\section{Perkembangan Dakwah Muhammadiyah di Kecamatan Tombolo Pao}

Muhammadiyah merupakan organisasi kegamaan dalam masyarakat yang paling tua di Indonesia. Didirikan pada tahun 1912 oleh KH Ahmad Dahlan yang pada saat itu menamai dirinya dengan tajdid (pembaruan). Muhammadiyah merupakan gerakan Islam dan dakwah amar ma'ruf nahi munkar yang semuanya bersumber dari Al-qur'an dan As-Sunnah serta menuju jalan yang diridhoi Allah SWT. Gerakan Islam yang senantiasa istiqamah mengemban misi dakwah dan tajdid untuk mewujudkan peradaban yang utama (Karim dkk, 2021). Gambaran perkembangan Muhammadiyah di daerah terutama di Kecamatan Tambolo Pao tidak semudah yang dibayangkan. Termasuk dalam menjaga aset-aset yang ada, dan dipertahankan serta ditingkatkan adalah tantangan tersendiri (Barrimi et al., 2013). Orientasi gerakan keagamaan dakwah Muhammadiyah yakni merujuk pada ajaran Salafiyah dengan melakukan purifikasi atau pemurnian. Misalnya di bidang akidah dan juga ibadah dengan tujuan menciptakan masyarakat mardlatillah, yang merupakan implementasi prinsip amar ma'ruf nahi munkar. Muhammadiyah Tambolo Pao mengalami perkembangan yang signifikan baik dari segi organisasinya maupun amal usahanya.

Masyarakat yang beragam cukup mewakili Citra tentang Muhammadiyah. Paling tidak terdapat tiga interpretasi yang berbeda tentang organisasi yang telah berusia lebih dari satu abad tersebut; (1) Muhammadiyah merupakan sebuah organisasi sosial pendidikan. Citra ini sebagai bentuk apresiasi dari segala kegiatan Muhammadiyah yang paling nyata di bidang pendidikan; (2) Muhammadiyah digunakan sebagai gerakan dakwah amar ma'ruf nahi munkar. Dalam gerakan ini terdapat dua aspek, yaitu pembelaan tentang pemurnian iman ke arah tauhid yang murni dan anjuran menjalankan akhlak mulia; (3) Muhammadiyah sebagai gerakan sosial keagamaan. Wujud gerakan ini yang menonjol ada dua, diantaranya pendirian panti-panti asuhan anak yatim piatu, balai pengobatan dan rumah sakit, mobilisasi zakat, infaq, sodaqoh serta wakaf (Afnan, 2015).

Perkembangan Muhammadiyah dapat dilihat dari peran Muhammadiyah yang sudah nampak sejak awal pendiriannya. Muhammadiyah metitikberatkan perannya pada semua aspek kehidupan sosial melalui usaha dakwah tabligh, pengajian, pembinaan keluarga muslim dan pendidikan. Hal ini sejalan ditunjukkan dengan telah berdirinya sekolahsekolah Muhammadiyah yang merupakan wahana untuk memajukan bangsa yang sebagian besar beragama Islam, agar tidak terkungkum dalam lingkungan kultural yang tradisional, tertutup, dan tertinggal oleh tuntutan dan kemajuan zaman (Edyanto, 2019). Peran tersebut tidak terlepas dari maksud dan tujuan pendirian organisasi Muhammadiyah sendiri. Hal ini dalam rangka menegakkan dan menjunjung tinggi agama Islam semata-mata demi terwujudnya 'Izzul Islam wal Muslimin, kejayaan Islam sebagai realita dan kemuliaan hidup umat Islam (Tahang et al., 2019).

Dalam perkembangannya, amal usaha Muhammadiyah yang pertama dilakukan yakni usaha dalam mendirikan sekolah dan menyelenggarakan pangajian (pengajaran Islam/tabligh). Selain itu, terdapat usaha dibidang pendidikan, penyiaran Islam dan tabligh meluas memasuki bidang kesehatan dan kesejahteraan ekonomi (Wiwoho, 1993). Adapun 
gerakan Muhammadiyah sendiri berciri semangat membangun tata sosial dan pendidikan masyarakat yang lebih maju dan terdidik. Kemudian menampilkan ajaran Islam bukan sekedar agama yang bersifat pribadi dan statis, melainkan dinamis dan berkedudukan sebagai sistem kehidupan manusia dalam segala aspeknya (Maulana, 2017). Oleh karena itu untuk mengetahui peranan Muhammadiyah terlebih dahulu harus di pahami apa yang menjadi amal usaha Muhammadiyah. Berikut amal usaha persyarakitan Muhammadiyah sejak sejak didirikannya yang di jelaskan dalam AD/RT PP Muhammadiyah 2001:

1. Menyebarluaskan agama terutama dengan mempergiat dan menggembirakan tabligh.

2. Memperdalam pengkajian ajaran Islam untuk mendapatkan kemurnian dan kebenaran.

3. Memperteguh iman, mempergiat ibadah, meningkatkan semangat jihad dan mempertinggi akhlak.

4. Memajukan dan memperbaharui pendidikan dan kebudayaan, mengembangkan ilmu pengetahuan, teknologi, seni serta mempergiat penelitian menurut tuntunan Islam.

5. Membimbing masyarakat untuk berwakaf serta membangun dan memelihara tempat ibadah.

6. Meningkatkan harkat dan martabat manusia menurut tuntunan Islam.

7. Membina dan menggerakkan generasi mudah agar menjadi muslim yang berguna bagi agama, nusa dan bangsa.

8. Membina masyarakat kearah perbaikan kehidupan dan mengembangkan ekonomi sesuai ajaran Islam.

9. Memelihara, melestarikan, memberdayakan kekayaan alam untuk kesejahteraan masyarakat.

10. Membina dan memberdayakan petani, buruh, nelayan, pedagang kecil untuk meningkatkan taraf hidupnya.

11. Menjalin dunia kemitraan dengan dunia usaha.

12. Membimbing masyarakat dalam menunaikan zakat, infaq, sedeqah, hibah dan wakaf.

13. Mengembangkan budaya tolong menolong dalam kebajikan dan taqwa dalam bidang kesehatan, sosial, pengembangan masyarakatdan keluarga sejahtera.

14. Menumbuhkan dan meningkatkan ukhuwah islamiyah dan kekeluargaan dalam Muhammadiyah.

15. Menanamkan kesadaran agar tuntunan dan peraturan Islam diamalkan dalam masyarakat.

16. Memantapkan kesatuan dan persatuan bangsa serta peran dalam berbangsa dan bernegara (Muhammadiyah, 2001).

Disamping mempunyai tugas atau bentuk usaha, perlu diketahui bahwasanya bentukbentuk usaha tersebut di dasarkan pada cita-cita perjuangan yang artinya dalam menjalankan usaha harus berpedoman pada cita-cita perjuangan Muhammadiyah. Adapun Program Dasar Perjuangan Muhammadiyah yaitu:

1. Muhammadiyah berjuang untuk meweujudkan suatu cita-cita dan keyakinan hidup yang bersumber dari ajaran Islam.

2. Dakwah Islam dan amar ma'ruf nahi munkar dalam arti yang sebenar-benarnya sebagaimana yang di tuntunkan oleh Nabi Muhammad SAW.

3. Dakwah Islam dan amar ma'ruf nahi munkar harus melalui dua saluran seperti saluran politik (politik praktis) dan saluran masyarakat. 
4. Muhammadiyah dan partai tidak ada hubungan organisasi tetapi tetap mempunyai hubungan ideologis.

5. Berjalan sendiri-sendiri tetapi memiliki rasa pengeritian untuk mewujudkan tujuan masing-masing.

Berkembangnya Dakwah Muhammadiyah di Kecamatan Tombolo Pao, tidak terlepas dari sumbangan tenaga dan pikiran dari Samiun sehingga Muhammadiyah dapat di kenal dan diterima oleh Masyarakat. Usaha-usaha yang Samiun lakukan untuk memperkenalkan Muhammadiyah diantaranya dengan membangun Madrasah di Kampung Datarang yang dipimpin langsung oleh Samiun. Saat itu Samiun juga merubah Khutbah Jum'at dari Bahasa Arab yang tidak dimengerti sebagian masyarakat menjadi bahasa Makassar (konjo) sebagai bahasa sehari-hari masyarakat. Pada tahun 1962, berdiri perserikatan Muhammadiyah yang disebut Muhammadiyah Ranting Pao Tombolo. Ide-ide perubahan yang dicita-citakan oleh Samiun kemudian dilanjutkan oleh orang-orang yang sebelumnya pernah menimba ilmu dari Samiun ketika Samiun mendirikan Madrasah di Datarang antara lain Barang Kasim, Kadir Oda, B.Thalib dan Kasim Kari.

Setelah berhasil mendirikan Muhammadiyah Ranting Pao Tombolo yang berada dalam binaan cabang Sungguminasa, tokoh-tokoh pendiri tersebut merasa perlu untuk mengembangkan ranting tersebut dalam rangka mengembangkan perjuangan dakwah Muhammadiyah. Maka pada tahun itu juga mereka mengirim beberapa pemuda-pemuda yang mempunyai pemikiran serupa untuk memperdalam ilmunya diperguruan Muallimin Muhammadiyah Jongaya Mamajang, belum lagi kembalinya Nadjamuddin yang juga anak tertua Samiun dari pernikahannya yang kedua dengan Syamsiah setelah menuntut ilmu di Makassar (Nursyamsi, 2019).Dalam rangka menigkatkan kerja dakwah Muhammadiyah cabang Tombolo Pao, maka pada tahun yang sama juga diresmikan ranting Muhammadiyah Tombolo Pao, delapan ranting-ranting tersebut adalah:

1. Ranting Datarang, Ketua Thalib

2. Ranting Cengkong, Ketua Genda

3. Ranting Bontolebang Ketua Kadir Dobo

4. Ranting Pa'barung, Ketua Tajang

5. Ranting Balasuka, Ketua Senggong

6. Ranting Bontopanno, Ketu Jafar Toto

7. Ranting Matteko, Ketua Palele

8. Ranting Benga, Ketua Asse'

9. Ranting Bongki, Ketua Abdul kadir L

Adapun upaya Pimpinan cabang Muhammadiyah (PCM) Tombolo Pao dalam pembinaan masyarakat serta pengembangan dakwah di kecamatan Tombolo Pao Kabupaten Gowa yaitu:

1. Bidang keagamaan

Bidang agama adalah pusat dari segala kegiatan Muhammadiyah, dasar dan jiwa dari setiap amal Muhammadiyah. Apa yang dilakukan di bidang lain adalah dorongan keagamaan baik karena kegiatan pendidikan maupun sosial. Seperti perjuangan atau usaha Muhammadiyah di daerah lain. Muhammadiyah di kecamatan Tombolo Pao dalam aspek keagamaan berupaya memberantas syirik, takhayul, bid'ah, dan khurafat. Muhammadiyah di daerah ini juga berusaha meluruskan dan mengarahkan pelaksanaan syariat Islam baik dalam ibadah maupun muamalat, serta berusaha mendorong masyarakat Islam di 
Kecamatan Tombolo Pao untuk beramal dan ibadah melalui tabligh-tabligh atau pengajian yang dilakukan oleh para da'i di Kecamatan Tombolo Pao. Ada beberapa aspek dalam bidang keagamaan Muhammadiyah sebagai organisasi dan gerakan Islam menjalankan dakwah dengan melaksanakan ajaran Islam yang meliputi:

a. Aqidah, dimana Muhammadiyah menegakkan aqidah Islam yang murni dan besih dari kemusyrikan, bid'ah, khurafat, dengan menerapkan tidak adanya toleransi bagi pelaku.

b. Akhlak, dimana Muhammadiyah menegakkan sendi-sendi akhlak yang mulia dengan berpedoman kepada Al-Qur'an dan As-Sunnah.

c. Ibadah, Muhammadiyah menegakkan ibadah berdasarkan tuntunan Rasulullah SAW tanpa adanya tambahan dan pengurangan yang dibuat-buat manusia.

d. Muamalah, Muhammadiyah menjalin hubungan terhadap sesama manusia dengan baik seperti dalam bidang ekonomi, sosial, politik dan lain-lain.

Dalam bidang keagamaan, terdapat beberapa contoh kegiatan yang dilakukan Muhammadiyah di Kecamatan Tombolo Pao antara lain:

a. Mendirikan masjid sebagai pusat gerakan dakwah

Setelah organisasi terbentuk, maka perlu adanya sebuah tempat atau pusat dalam usaha menyebarkan ajaran Muhammadiyah, yaitu dengan mendirikan dan mengunakan masjid sebagai basis dakwah. Masjid yang dimaksud adalah masjid Babul Firdaus yang berada di Datarang, menurut salah satu tokoh Muhamadiyah di Datarang (Drs. H Zainuddin), bahwa Masjid tersebut sebenarnya bukanlah Masjid yang dibangun oleh Muhammadiyah. Tetapi karna berada di Datarang yang merupakan pusat dakwah Muhammadiyah, maka Masjid tersebut kemudian dijadikan sebagai tempat pengajian warga Muhammadiyah yang pada tahun 1962 juga diresmikan sebagai masjid amal usaha Muhammadiyah ranting Pao Tombolo.

b. Mengisi ceramah/khutbah di Masjid

Pimpinan Cabang Muhammadiyah (PCM) Pao Tombolo juga mempunyai jadwal ceramah di masjid di setiap desa dan wilayah di kecamatan Tombolo Pao, baik itu masjid binaan Muhammadiyah ataupun masjid umum. Pimpinan Cabang Muhammadiyah juga mempunyai jadwal ceramah selain di Kecamatan Tombolo Pao. Selain itu pada saat bulan Ramadan Pimpinan Cabang Muhammadiyah juga mempunyai jadwal ceramah yang tetap.

c. Dakwah di ladang dengan para petani.

Pimpinan Cabang Muhammadiyah juga menerapkan pembinaan di sawah dan ladang dengan para petani dengan diskusi bebas dan bertukar pikiran dengan para petani. Adanya kegiatan tersebut Pimpinan Cabang berharap dapat digunakan sebagai sarana diskusi sehingga dapat menghasilkan solusi dari permasalahan yang dihadapi oleh para petani (Abdul Malik, wawancara: 2020).

d. Mengadakan pengajian

Pimpinan Cabang Muhammadiyah memiliki pengajian rutin setiap sekali sebulan. Melalui pengajian tersebut Pimpinan Cabang Muhammadiyah mengundang kepada seluruh masyarakat agar menghadiri pengajian. Inti dari kegiatan tersebut yakni Pimpinan Cabang Muhammadiyah (PCM) Pao Tombolo melaksanakan pembinaan kepada masyarakat. Beberapa Majelis Taklim yang sering diselenggarakan oleh Pimpinan Cabang Muhammadiyah diantaranya Majelis Ta'lim Ranting Pa'barung, Majelis Ta'lim Ranting Ballasuka, Majelis Ta'lim Ranting Maroanging, Majelis Ta'lim Ranting Pao, Majelis Ta'lim 
Ranting Lembang.

e. Penmulasaran Jenazah

Kegiatan rutin yang dilaksanakan oleh Pimpinan Cabang Muhammadiyah (PCM) Tombolo Pao yaitu mengadakan penyelengaraan jenazah kepada masyarakat. Kegiatan tersebut sering di selengarakan oleh majelis ta'lim lalu mengundang ustadz dari Muhammadiyah sebagai pemateri.

2. Bidang Pendidikan

Pendidikan merupakan sesuatu yang sangat penting bagi manusia, karena dengan melalui pendidikan, manusia bisa menghadapi perkembangan alam semesta untuk mempertahankan kehidupan dan perkembangan zaman. Islam menempatkan pendidikan pada kedudukan yang penting dan tinggi dalam doktrin Islam (Mattayang, 2014). Melalui pendidikan pula, jiwa manusia dapat diwarnai dengan akhlak dan perbuatan yang mulia. Oleh sebab itu sekolah yang didirikan Muhammadiyah di Kecamatan Tombolo Pao pada umumnya serta di daerah ranting pada khususnya bukan hanya untuk berdakwah, tetapi berfungsi untuk pembinaan kader-kader Muhammadiyah dimasa yang akan datang, sekaligus sumbangsi Muhammadiyah terhadap Bangsa dan Negara.

Tujuan umum lembaga pendidikan Muhammadiyah, sebagaimana yang telah tercantum dalam Mukhtamar Muhammdiyah ke-38 di Ujung pandang tahun 1975 yaitu sebagai berikut :

a. Terwujudnya manusia Muslim yang berakhlaq mulia, cakap, percaya diri sendiri dan berguna bagi masyarakat dan Negara, beramal menuju terwujudnya masyarakat Islam yang sebenar-benarnya.

b. Memajukan dan memperkembangkan ilmu pengetahuan dan keterampilan untuk pembangunan masyarakat dan Negara Republik Indonesia yang berdasarkan pancasila dan Undang-Undang Dasar 1945 (Muhammadiyah, 2006).

Pendidikan merupakan sesuatu yang esensial atau bagian dasar yang sangat diperlukan. Bagi sekelompok orang, melalui pendidikan manusia bisa menghadapi alam semesta demi mempertahankan kehidupannya. Oleh karena itu, dalam Islam pentingnya pendidikan membuatnya terletak pada kedudukan yang sangat penting. Secara ideal pendidikan akan mengarahkan dan membentuk manusia menjadi khalifah fil ardh (Haedar Nashir, 2010). Dalam hal ini harus mencakup antara ukhrawi (akhirat) dan duniawi, fisik dan mental, intelektual dan spiritual yang berarti harus terpadu antara ilmu agama dan ilmu umum (Mattayang, 2014).

Dalam bidang pendidikan Muhammadiyah telah aktif dalam pendidikan sejak 1935, hanya saja perkembangannya pada tahun 1952 yakni setelah Indonesia merdeka. Itupun baru mempunyai tingkat Ibtidaiyah (SD), pada 1957 baru Muhammadiyah mendirikan sekolah tingkat Tsanawiyah (SMP) dan ini pun masih harus belajar di kolong rumah karena belum mempunyai gedung, dan pada tahun 1959 baru mempunyai gedung sendiri (Saling Sattuan, 1985). Beberapa Lembaga Pendidikan yang didirikan oleh Muhammadiyah Cabang Pao Tombolo adalah Madrasah Aliyah (MA) Datarang, Madrasah Aliyah (MA) Ballasuka, Madrasah Tsanawiyah (MTS Datarang), Madrasah Tsanawiyah (MTS) Ballasuka, SD Muhammadiyah Datarang, TK Aba II Ballasuka, TK Aba III Tombolo, TK Aba IV Lembang, TK Aba 5 Buki.

Selain sekolah, Muhammadiyah juga menekankan perhatian serius kepada anak usia 
dini, yaitu dengan melakukan Pembinaan usia dini (pembinaan TK/TPA). Pembinaan usia dini yang di jalankan oleh Pimpinan Cabang Muhammadiyah (PCM) Tombolo Pao yaitu mengajar di Taman kanak-kanak dan mengajar di TPA yang ada di kecamatan Tombolo Pao. Selanjutnya dalam usaha pemberantasan penyakit-penyakit masyarakat Islam seperti takhayul, bid'ah, dan khurafat, Muhammadiyah dapat dikatakan berhasil. Hal ini dijelaskan oleh Abdul Malik, bahwa pengaruh Muhammadiyah di Tombolo Pao t erhadap pemahaman agama di Tombolo Pao khususnya di Desa Ballasuka. Selain ranting pertama, Muhammadiyah di Ballasuka juga berhasil memberantas praktik-praktik keagamaan yang menyimpang, capaian yang dimaksud adalah berhasil menghancurkan/menghilangkan tempat-tempat yang dijadikan pesugihan yang kemudian tempat itu pohon besarnya dihilangkan dan kemudian didirikan masjid yang sampai sekarang ini tetap berdiri (Abdul Malik, wawancara: 2020).

Abdul Kadir selaku bendahara umum Pimpinan Cabang Muhammadiyah (PCM) Pao Tombolo mengungkapkan strategi komunikasi pembinaan masyarakat yang sudah di katakan berhasil dan sudah berjalan sampai sekarang yaitu dari segi komunikasi face to face yang dilaksanakan oleh Pimpinan Cabang Muhammadiyah di bidang pendidikan dan strategi komunikasi face to face yang dilaksanakan di Majelis Taklim, bukti dari keberhasilannya sampai sekarang yaitu masih berdirinya sekolah-sekolah binaan Pimpinan Cabang Muhammadiyah. Selaian itu juga masih aktifnya pengajian-pengajian yang sering diselenggarakan oleh Pimpinan Cabang Muhammadiyah Pao Tombolo (Abdul Kadir, wawancara: 2020).

\section{Pandangan Mayarakat Tentang Muhammadiyah}

Di Kecamatan Tombolo Pao terdapat banyak organisasi Islam yang berkembang seperti, Wahdah Islamiyah, Nahdatul Ulama, As-Sunnah, dan Jamaah Tabligh. Dalam hal keagamaan, Muhammadiyah mendapatkan posisi khusus di tengah masyarakat. Menggunakan metode dakwah yang diterapkan, Muhammadiyah telah mampu mengubah masyarakat yang dahulunya masih banyak melakukan kemusyrikan hingga sekarang meninggalkan perbuatan tersebut. Strategi komunikasi dalam pembinaan masyarakat yang dilakukan oleh Muhammadiyah di Kecamatan Tombolo Pao sangat terstruktur dan menjangkau semua kalangan yang ada. Pada tubuh Muhammadiyah juga terdapat organisasi Ikatan Pelajar Muhammadiyah, sebagai pencetak generasi Muda Muhammadiyah di tingkat pelajar, ada Pemuda Muhammadiyah, sebagai pencetak generasi di tingkat pemuda. Selain itu Muhammadiyah juga mendirikan sekolah-sekolah sebagai wadah bagi masyarakat untuk mengembangkan ilmu pengetahuan dan mengadakan pengajianpengajian di kalangan masyarakat (Harun, wawancara: 2020).

Muhammadiyah tidak begitu memiliki hambatan yang sulit dalam hal pembinaan di masyarakat, terutama di Kecamatan Tambolo Pao. Karena di setiap kegiatan keagamaan yang dilakukan di masyarakat, mayoritas kader Muhammadiyah yang memberikan materi kepada kegiatan keagamaan yang dilakukan masyarakat. Tetapi, seiring berkembangnya waktu, kini Muhammadiyah Cabang Tambolo Pao sudah diakui oleh pemerintah sebagai lembaga atau organisasi yang resmi. Bahkan kader-kader dari Muhammadiyah sudah banyak yang sukses dan banyak dimanfaatkan di masyarakat, seperti mengajar di sekolahsekolah, mengisi pengajian-pengajian dan mengisi kegiatan keagamaan lainnya. 


\section{KESIMPULAN}

Tokoh perintis Muhammadiyah di Tombolo Pao adalah Samiun yang merupakan seorang guru yang berasal dari Bonthain (Bantaeng) yang ditugaskan oleh pemerintah Belanda di Distrik Pao untuk mengajar di sekolah rakyat bersama dua rekannya yang bernama Mangngamporang dan Ba'do pada tahun 1935. Pada sekitar awal tahun 1940-an, melalui Samiun, didirikanlah sebuah organisasi Islam, yaitu Muhammadiyah sebagai wadah atau media dalam mengembangkan paham dan ajaran Muhammadiyah yang disebut dengan Pimpinan Cabang Muhammadiyah Pao Tombolo yang masih terkenal hingga sekarang.

Pada tahun 1962, berdiri perserikatan Muhammadiyah dengan nama Muhammadiyah Ranting Pao Tombolo. Ide-ide perubahan yang dicita-citakan oleh Samiun kemudian dilanjutkan oleh orang-orang yang sebelumnya pernah menimba ilmu dari Samiun ketika Samiun mendirikan Madrasah di Datarang antara lain Barang Kasim, Kadir Oda, B.Thalib dan Kasim Kari. Upaya Pimpinan cabang Muhammadiyah (PCM) Pao Tombolo dalam pembinaan masyarakat di kecamatan Tombolo Pao Kabupaten Gowa dibagi kedalam dua aspek atau bidang; pertama, melalui bidang keagamaan Muhammadiyah difokuskan kepada pemberantasan kegiatan syirik, takhayul, bid'ah dan khurafat yang dianut oleh sebagian besar masyarakat di kecamatan Tombolo Pao. Selain itu, Muhammadiyah juga aktif dalam meluruskan dan mendorong masyarakat dalam melakukan syariat, ibadah dan muamalat yang baik dan benar sesuai tuntunan Al-Qur'an dan As-sunnah yang menjadi landasan dakwah Muhammadiyah. Dalam bidang keagamaan, Muhammadiyah menjadikan masjid sebagai pusat dakwah, kader muhammadiyah juga mnejadi da'i atau khatib dalam setiap kegiatan keagamaan, mengadakan pengajian dan tablig akbar, serta aktif dalam beberapa kegiatan sisial kemasyarakatan.

Kedua, melalui pendidikan; yaitu tertuang dalam keputusan muktamar muhammadiyah ke-38 di Ujung Pandang tahun 1975 yang termanifestasikanndalam beberapa aspek fisik berupa pembentukan sekolah sekolah muhammadiyah, pembinaan taman kanak-kanak, serta aktif dalam mengajar dan memberukan pendidikan kepada siswa bianaan sekolah Muhammadiyah. Lembaga Pendidikan yang didirikan oleh Muhammadiyah Cabang Pao Tombolo adalah Madrasah Aliyah (MA) Datarang, Madrasah Aliyah (MA) Ballasuka, Madrasah Tsanawiyah (MTs Datarang), Madrasah Tsanawiyah (MTs) Ballasuka, SD Muhammadiyah Datarang, TK Aba II Ballasuka, TK Aba III Tombolo, TK Aba IV Lembang, TK Aba 5 Buki. Sebagai organisasi keagamaan, Muhammadiyah dituntut dan perlu beradaptasi dengan perkembangan sains dan teknologi era modern. Salah satunya dengan melahirkan dan menciptakan inovasi-inovasi serta terobosan baru dalam proses mencapai cita-cita dan tujuan Muhammadiyah agar tetap diakui keberadaannya di Masyarakat Tombolo Pao pada Khsusnya dan masyuarakat Indonesia Pada umumnya.

\section{DAFTAR PUSTAKA}

Afnan, M. (2015). Perkembangan Muhammadiyah Di Mojokerto Tahun 1990-2012. AVATARA, e-Journal Pendidikan Sejarah, 1(3), 2005-2010.

Al-Qaradhawi, Y., Riswanto, A. M., \& Akaha, A. Z. (2005). Distorsi Sejarah Islam. Pustaka AlKautsar. 
Barrimi, M., Aalouane, R., Aarab, C., Hafidi, H., Baybay, H., Soughi, M., Tachfouti, N., Nejjari, C., Mernissi, F. Z., Rammouz, I., \& McKenzie, R. B. (2013). Encephale, 53(1), 59-65. http://dx.doi.org/10.1016/j.encep.2012.03.001

Edyanto, K. (2019). Peran Muhammadiyah Dalam Pemberdayaan Masyarakat Kokoda Di Kota Sorong. Jurnal Noken: Ilmu-Ilmu Sosial, 4(1), 23. https://doi.org/10.33506/jn.v4i1.360

Haedar Nashir. (2010). Manhaj Gerakan Muhammadiyah. Suara Muhammadiyah.

Karim, A., Adeni, A., Fitri, F., Fitri, A., Hilmi, M., Fabriar, S., \& Rachmawati, F. (2021). Pemetaan untuk strategi dakwah di Kota Semarang menggunakan pendekatan data mining. Jurnal Dakwah Risalah, 32(1). doi:http://dx.doi.org/10.24014/jdr.v32i1.12549

Karim, A., Suharno, Y., \& Arwani, W. (2019). Pemberdayaan Sekolah Islam untuk Meningkatkan Kompetensi Profesionalisme Guru di Kabupaten Semarang. Jurnal Ilmu Dakwah, 39(1), 91-100. DOI : 10.21580/jid.v39.1.4421.

Lubis, A. (1993). Pemikiran Muhammadiyah dan Muhammad Abduh: Suatu Studi Perbandingan (Cet. I). Bulan Bintang.

Mattayang, B. B. (2014). Mentari Bersinar di Gowa: Menelusuri Jejak Kehadiran Muhammadiyah Di Gowa tahun 1928-1968 (Cet. I). Goresan Pena.

Maulana, M. S. R. (2017). No TitleÉ? Ekp, 13(3), 1576-1580.

Muhammadiyah, P. P. (2001). Anggaran Dasar dan Anggaran Rumah Tangga Muhammadiyah.

Muhammadiyah, P. P. (2006). Himpunan Putusan Tarjih. Yogyakarta: PP. Muhammadiayh, $\mathrm{Nd}$.

Mulkhan, A. M. (1994). Masalah-masalah teologi dan fiqh dalam Tarjih Muhammadiyah. Roykhan.

Musriadi. (2016). Profesi Kependidikan Secara Teoritis dan Aplikatif Panduan Praktis bagi Pendidik dan Calon Pendidik. Deepublish (Grup Penerbitan CV Budi Utama).

Nursyamsi, N. (2019). Peranan Muhammadiyah dalam Pembinaan Masyarakat Islam di Desa Balassuka Kecamatan Tombolo Pao Kabupaten Gowa pada Masa Orde Baru (Suatu Tinjauan Historis). Universitas Islam Negeri Alauddin Makassar.

Pasha, M. K., \& Darban, A. (2000). Muhammadiyah sebagai gerakan Islam: dalam perspektif historis dan ideologis. LPPI, Universitas Muhammadiyah Yogyakarta.

Radjab, W. (1999). Lintasan Perkembangan dan Sumbangan Muhammadiyah di sulawesi Selatan. IPPSDM-WIN.

RI, K. A. (2010). Al Quds: al-Qur'an dan Terjemah Dilengkapi dengan Asbabun Nuzul dan Hadits Shahih. Sygma Exagrafika.

Shobron, S., \& Azmi, M. (2011). Eksistensi Muhammadiyah Dan Nahdhatul Ulama Di Desa Plompong, Sirampog, Brebes, Jawa Tengah (Studi Perbandingan). 187-206.

Suyuthie, H. (2010). Refleksi Satu Abad Muhammadiyah. PWM B-Press.

Tahang, H., Wekke, I. S., \& Fatimah, F. (2019). Dakwah Muhammadiyah Melalui Lembaga Pendidikan. 1-17. https://doi.org/10.31227/osf.io/scjnq

Wiwoho, B. (1993). Muhammadiyah dalam Sorotan. Bina Rena Pariwara. 